\title{
To Measure the Changing Relief of Arctic Rivers: A Synthetic Aperture RADAR Experiment in Alaska
}

\author{
Reginald R. Muskett \\ Geophysical Institute, University of Alaska Fairbanks, Fairbanks, AK, USA \\ Email: reginald.muskett@gmail.com
}

How to cite this paper: Muskett, R.R. (2018) To Measure the Changing Relief of Arctic Rivers: A Synthetic Aperture RADAR Experiment in Alaska. Journal of Geoscience and Environment Protection, 6, 207-222.

https://doi.org/10.4236/gep.2018.69016

Received: August 28, 2018

Accepted: September 27, 2018

Published: September 30, 2018

Copyright $\odot 2018$ by author and Scientific Research Publishing Inc. This work is licensed under the Creative Commons Attribution International License (CC BY 4.0).

http://creativecommons.org/licenses/by/4.0/

\begin{abstract}
This river crossing the lowland tundra-permafrost of the continuous permafrost zone of the Alaska North Slope can have extensive floodplain relief not simply created by channel migration during spring floods alone. Many of the rivers have channel-beds inherited from glacial landscapes and Holocene to present-day paraglacial and periglacial processes and mountain gradient sources [1] [2] [3] [4]. Interest is turning to understand effects from permafrost and ice wedge networks (ground ice) thaw, degradation and erosion and how such effects impact carbon and water equivalent mass balance. The 2015 flooding of the Sagavanirktok River crossing the Alaska North Slope brings this and additional impacts to-and-by human infrastructure into focus. Geodetic methods to measure centimeter to millimeter-scale changes using aircraft- and satellite-deployed Synthetic Aperture (SA) RAdio Detection And Ranging (RADAR) cannot ignore volume scattering. Backscatter and coherence at L-frequency and others possess both surface and volumetric scattering. On lowland tundra underlain by permafrost volume scattering dominants the RADAR backscatter coherence (the results of this work and [16]). Measurement of the L-frequency penetration depth for evaluation of mass change (carbon and water equivalent loss and transport) through permafrost and ground ice thaw-degradation with erosion is necessary. The Jet Propulsion Laboratory-National Aeronautical and Space Administration airborne Uninhabited Aerial Vehicle SAR (UAVSAR) L-frequency full quad-polarimetry cross-pole HHVV (polarization rotation, Horizontal to Vertical) confirms the dominance of volume scattering on lowland tundra (RADAR-soft targets) whereas surface scattering (HHHH or VVVV, no rotation) dominates on river channel deposits, rock outcrops and metal objects (RADAR-hard targets). Quantifying polarization rotation and the L-frequency penetration depth on lowland tundra are challenges for a new field validation and verification experiment.
\end{abstract}




\section{Keywords}

Alaska, Tundra, Experiment, RADAR, Polarimetry

\section{Introduction}

Cold environment rivers e.g. those crossing the lowland tundra-permafrost of the continuous permafrost zone of the Alaska North Slope (Figure 1) can have extensive floodplain relief [1] [2] [3]. This is not simply created by channel migration during breakup-snowmelt floods. It has association with inherited glacial landscapes and present-day paraglacial and periglacial processes and mountain gradient sources [4]. In the lowland reach extensive thawponds and thermokarst features dominate such tundra-permafrost environments and often these are disconnected from the main river channel except during spring floods [3] [4].

The spring flooding of the Sagavanirktok River crossing the Alaska North Slope was first observed remotely by the NASA Earth Resources Technology Satellite (ERTS-1) on May 24 through May 27, 1973 (Figure 2 and Figure 3) [5]. Evidence of the flood visible in the imagery was confirmed on the ground by surveyors associated with work that would lead to the establishment of the Trans-Alaska Pipeline System by 1976. Interestingly as the Sagavanirktok River was flooding so too was the Canning River another major river originating in the Brooks Range, both were observed discharging onto the coast east of Prudhoe Bay of the Beaufort Sea. Floodwaters from both rivers in spring 1973 discharged onto the coastal sea ice.

The Sagavanirktok River experienced a noteworthy late-season August flood in 1992. This flood affected the entire reach from the uplands in the Brooks Range south of Atigun Pass to the coast of the Arctic Ocean [6]. This late-season flood was produced by precipitation in the Brooks Range and north across the foothills and coastal plain. Discharge and gage-height records at Pump Station 3 site 11 at 32 kilometers north of Atigun Pass shows a reoccurrence interval of 50 -years, whereas site 12 at 225 kilometers north of Atigun Pass the reoccurrence interval is 100 -years. At site 10 west of Deadhorse on the Kuparuk River,

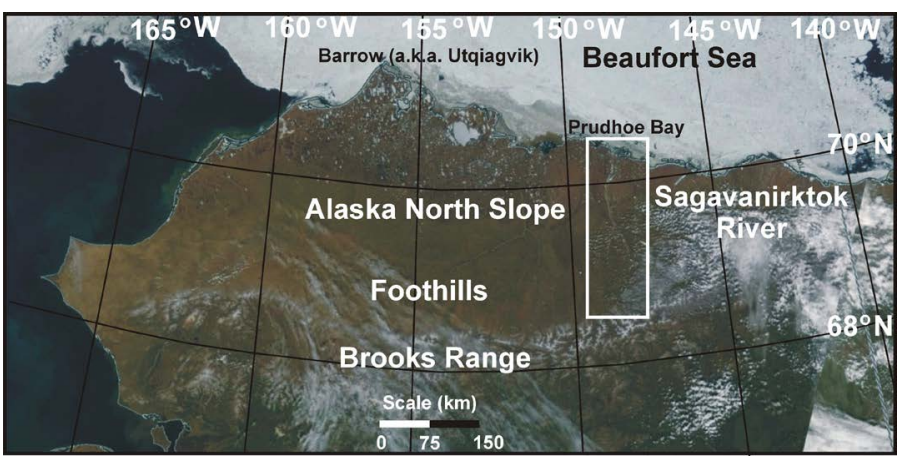

Figure 1. Alaska north slope and Sagavanirktok river. MODIS (17 June 2015) imagery. 


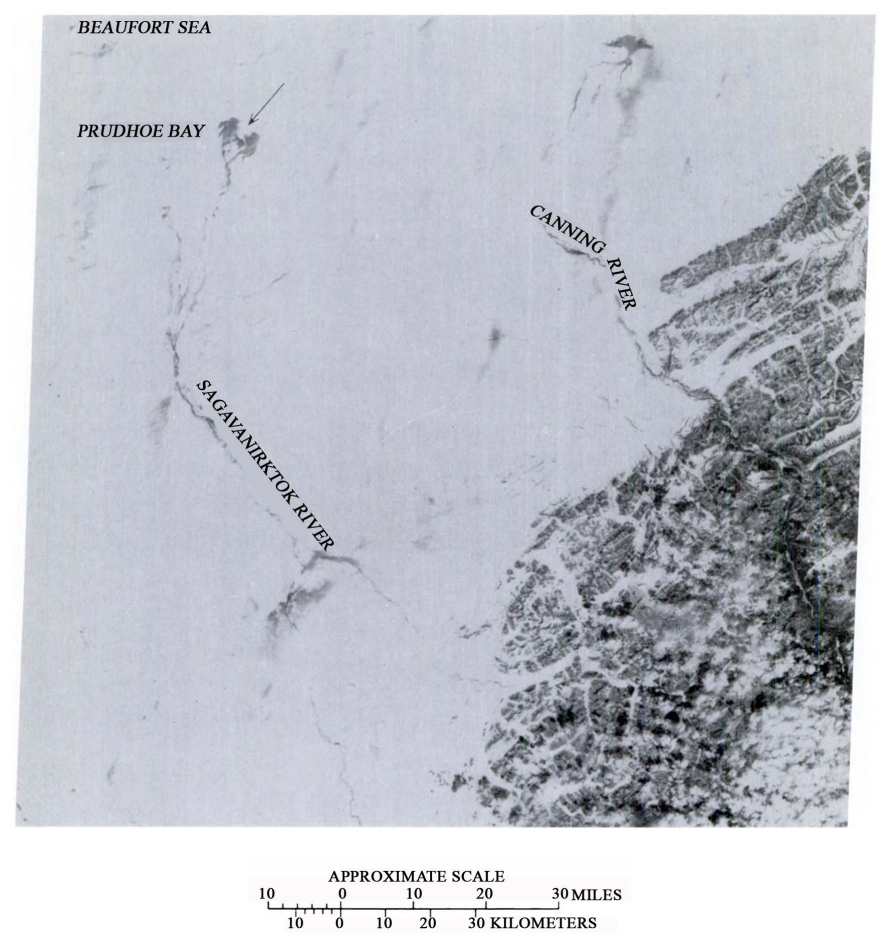

Figure 2. Earth Resources Technology Satellite-1 (ERTS-1, later LANDSAT1) image (Band 6, IR, 1307-21231 nm) showing flooding, 24 May 1973, of the Sagavanirktok River at Prudhoe Bay and the Canning River onto coastal sea ice of the Beaufort Sea, Alaska [5]. Note the dark-gray tones on the Brooks Range Mountains, indicative of an early season loss of snow cover.

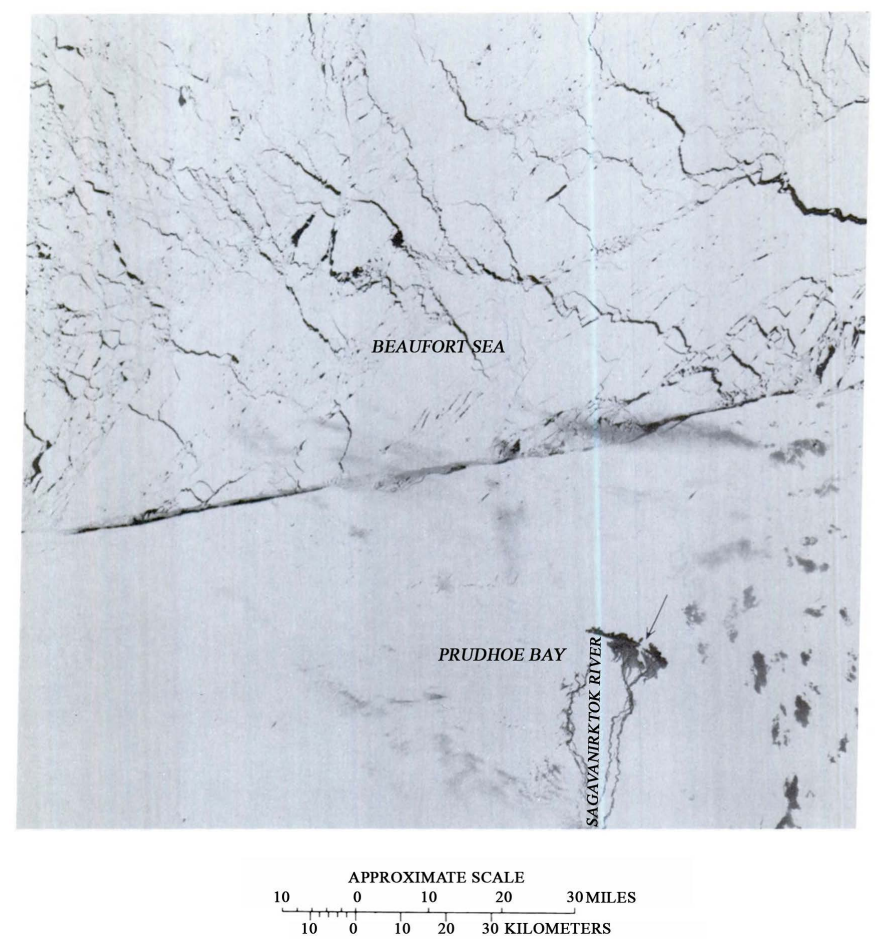

Figure 3. ERTS-1 image (Band 6, IR, 1307-21231 nm) of Sagavanirktok River at Prudhoe Bay 26 May 1973 [5]. 
16 kilometers from the Arctic Ocean, gage station records shows a reoccurrence interval of 2-years for the August flooding. At Deadhorse the August 1992 flood caused minor damage to roads and public facilities [6].

Beginning in March 2015 trucking company crews servicing Deadhorse and Prudhoe Bay oil field operations reported early-season breakup of river-ice high water of the Sagavanirktok River with sporadic overflow conditions along the Dalton Highway [7]. Due to high-water and overflow of the Dalton Highway the Alaska Department of Transportation and Public Facilities issued temporary-closures at affected highway sections during late March and early April [8]. On April 8 the Governor of Alaska and state officials declared a state of emergency and closure of the Dalton Highway [9].

USGS hydrologic monitoring at Pump Station 3 (148.818W 69.016N, NAD88, USGS 15908000) recorded high water levels near flood-stage in February with trace precipitation and air temperatures below freezing [10]. LANDSAT 8 images (Figure 4 and Figure 5) of the North Slope on April 1 through May 2015 showed extensive river-ice breakup along the entire length of the Sagavanirktok and Canning Rivers. The panchromatic (15 $\mathrm{m}$ resolution) and enhanced-resolution color images indicated negligible snow cover melting along the lower coastal

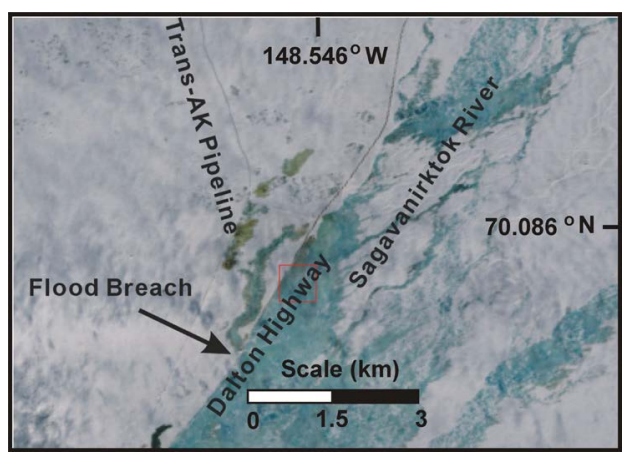

Figure 4. LANDSAT 8, flooding as of April 1, 2015. Snow-berm failure (arrow) and overflow of the Dalton Highway (west side) are shown. The red-box is a targeting gratule for data extraction.

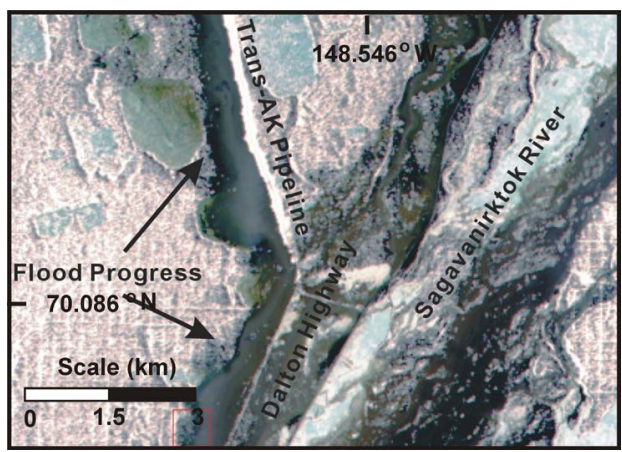

Figure 5. LANDSAT 8, flooding on May 19, 2015. Extensive flooding into the oil-field operations area is shown. Visible cross-hashed pattern is due to compacted snow by seismic-prospecting truck operations during winter months. The red-box is a targeting gratule for data extraction. 
plain and foothills reaches of the rivers. The upper Sagavanirktok and Canning near their headwaters in the Brooks Range showed extensive snow cover absence on south-facing slopes. NOAA National Weather Service diagnostic and outlook maps and reports indicated a persistent high-pressure weather system over eastern Alaska and western Canada during March and April allowed of cloud-free days [11]. The persistent cloud-free days and near-surface air temperature inversion lead to high-elevation snow cover melting. This early melting of the snow cover at the high-elevation generated runoff to the rivers and initiated the early-season river-ice breakup and subsequent flooding particularly along the coastal plain of Alaska.

At the height of the flooding the snow-berms which have been used to both add protection to the raised highway and confine flooding to the Sag flood plain failed at critical points to allow inundation behind the raised highway. Sections of the raised highway then failed producing rapid erosion and mass wasting of the tundra, active layer, ice wedge melt-out and permafrost thawing with degradation. Evidence suggests that a combination of natural early snowmelt onset and highway construction practices compounded to produce the effects as observed [12]. The Dalton Highway remained closed until June 5, 2015 [13]. One kilometer south of Dead horse extensive damage to the Dalton Highway and degradation-erosion of ice wedge patterned ground is visible in an a real image (Figure 6) taken by the Alaska Department of Transportation and Facility Services (AKDOTFS) on Friday, June 5, 2015 [14].

As seen in the image (Figure 6) the channel of the Sagavanirktok River is on the right, the new single-lane Dalton with an AKDOTFS truck and personnel setting warning cones are moving northeast. To the left of the truck is an area of

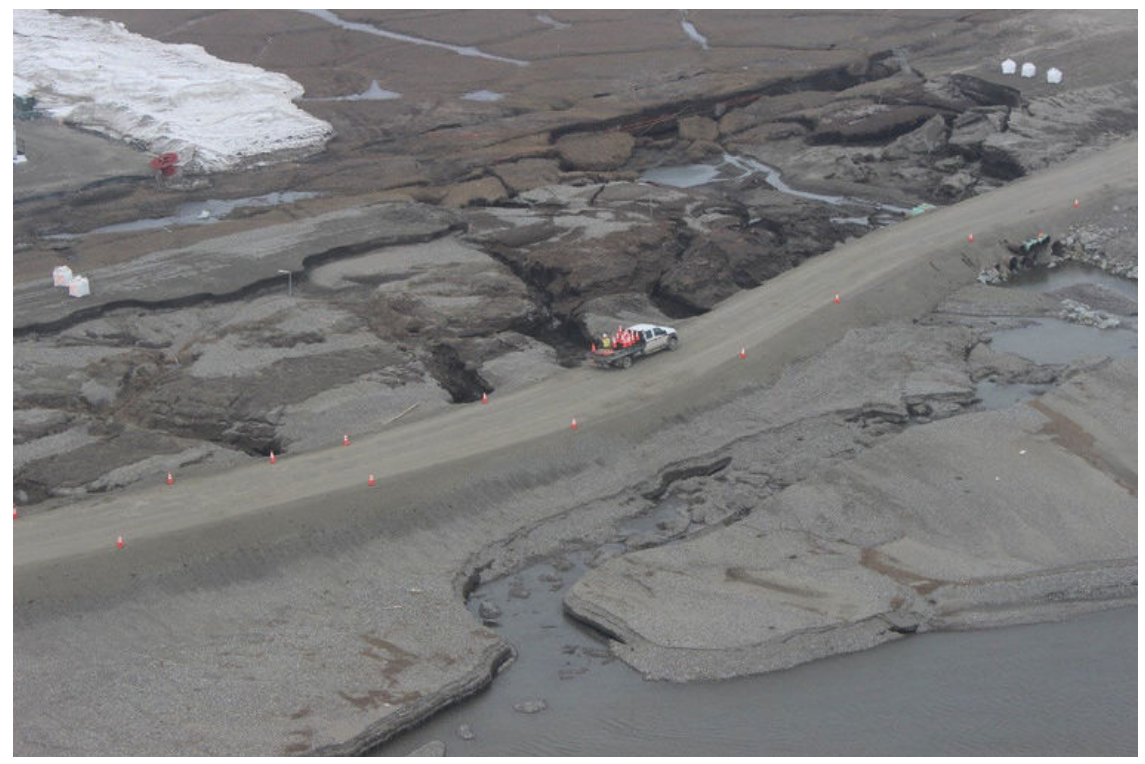

Figure 6. Erosion and degradation of ice wedge pattern ground network by the Sagavanirktok River flood June 5, 2015. Image by AKDOTFS and published by the Fairbanks News-Miner on June 5, 2015 [14]. 
extensive damage to the highway (with white pylon barriers), erosion of the tundra vegetation and active layer and extensive degradation-erosion of the ice wedges to several meters depth and degradation-erosion of enclosing permafrost. To the left of the damaged Dalton Highway can be seen the flooded ice wedge network south of the Deadhorse Airport. Using World View-3 images with $0.3 \mathrm{~m}$ resolution the width of the ice wedges averages 4 meters.

The advent of the Global Positioning System that is now part of the multi-system Global Navigation Satellite System (GNSS), airborne and satellite remote sensing with Digital Elevation Models (DEMs, and digital surface models) and erosion-surface and sediment dating have greatly facilitated dynamic-process studies of cold environment rivers (Levin and Ashworth, 2014) [3]. The focus of the research describe here it to investigate the Sagavanirktok River floodplain crossing the Alaska North Slope by using airborne fully polarmetric Synthetic Aperture RADAR (SAR) for retrieval of scattering by material type and changes of the relief relative to degradation of ice wedge polygons and permafrost. I will propose a new GNSS fine-scale geodetic network to test the SAR-derived results for validation and verification.

\section{Theory of Measurement}

RADAR (RAdio Detection and Ranging) is an electromagnetic oscillation (send and receive) that consists of the electric field and magnetic field at the speed of light (attenuated by atmosphere and low bulk density materials) [15]. The oscillations can be either plane polarized or circular polarized. The sigma naught backscatter (dB-scaled power) consists of the convolution of the spatial and temporal coherence functions. The spatial coherence is the convolution of the surface and volume coherence functions in a Bragg Scattering Law sense. When polarization can be decomposed into the fully polarized combinations of send and receive $\mathrm{HHHH}, \mathrm{VVVV}$ and HHVV for instance where $\mathrm{H}$ is horizontal and $\mathrm{V}$ is vertical oscillation the backscattering properties of the material can be distinguished as a RADAR-hard target with $\mathrm{H}$-send and -receive and $\mathrm{V}$-send and -receive (HHHH or VVVV) or a RADAR-soft target such that $\mathrm{H}$ or V-send becomes $\mathrm{V}$ or H-receive (HHVV for instance) in both the electric and magnetic field oscillations. RADAR-hard targets (HHHH or VVVV) do not produce rotation of polarization whereas RADAR-soft targets (HHVV) do produce rotation of polarization. Rotation of polarization is a product of volume scattering (i.e. penetration of the low bulk density material) whereas no-rotation of polarization is a product of surface scattering. Backscatter sigma-naught magnitude varies depending on whether from surface or volume scattering. This is illustrated by example in Figure 7.

Figure 7 shows the tundra and thaw lake landscape at the Next Generation Ecosystem Experiment (NGEE) site southeast of Barrow, Alaska. The three-channel image is composed of the sigma-naught representing in the Red-channel (HHHH) image, the Blue-channel (VVVV) image and the Green-channel 


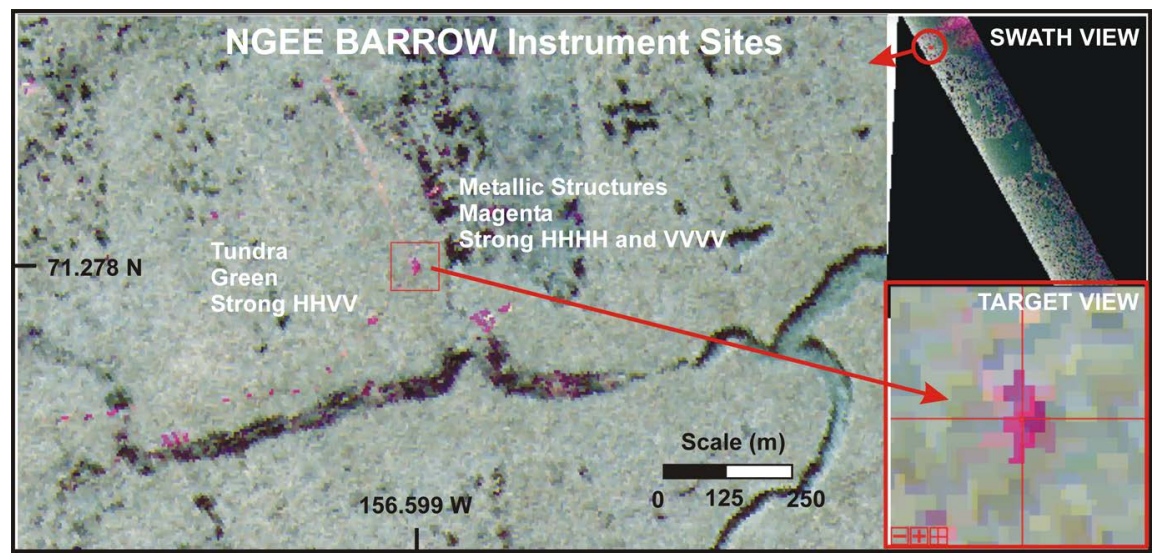

Figure 7. Three-channel composite of three backscatter sigma-naught images each with polarization: Red-channel HHHH, Blue-channel VVVV and Green-channel HHVV at 2 $\mathrm{m}$ resolution.

(HHVV) image. The image rasters of color magenta are the mixture of the Red HHHH and Blue VVVV. Metallic structures (high density materials) such as various meteorological equipment and towers are strong magenta color (Red $\sigma_{0}$ : $-1.408 \mathrm{~dB}$, Blue $\sigma_{0}:-7.796 \mathrm{~dB}$, Green $\sigma_{0}$ : NaN) whereas the tundra (short grasses, mineral and organic soil and shallow permafrost) is strong green color (Red $\sigma_{0}:-24.588 \mathrm{~dB}$, Blue $\sigma_{0}:-21.385 \mathrm{~dB}$, Green $\sigma_{0}:-25.726 \mathrm{~dB}$ ). Recall that $\mathrm{dB}$ is an inverse scale typically near zero $\mathrm{dB}$ to $-30 \mathrm{~dB}$ L-frequency on materials as these. Metal objects and other objects as river gravel bars and rock outcrops have strong surface scattering (no penetration). Tundra on the other hand interacts with the electric and magnetic fields polarizations to produce polarization rotation HHVV. Rotation of polarization is a signature of volume scattering (penetration of the low bulk density material). The sigma-naught of each polarization combination image (Red, Blue, Green) is different at the same physical location! This confirms the conclusion of the preceeding investigation comparing colocated elevation changes derived by the Ice, Cloud and land Elevation Satellite Geoscience Laser Altimeter System (ICESat GLAS) surface scattering to line-ofsight changes derived by the Advanced Land Observing Satellite Phased Array L-band Synthetic Aperture RADAR (ALOS PALSAR) volume scattering on the Alaska North Slope tundra and river channel deposits of the Anaktuvuk wildfire burn scar [16].

Satellite borne L-frequency SAR penetration of low bulk density earth materials was first demonstrated during the Shuttle Transportation System (STS) Flight 2, November 1981 using the Jet Propulsion Laboratory Space Imaging RADAR-A while overpassing the Sahara Desert in Egypt [17] [18] [19] [20]. Direct measurement of airborne or satellite borne L-frequency SAR on tundra-permafrost terrains has not been attempted. In particular for satellite borne SAR system having the availability of full polarimetry has only become available in the recent ALOS-2 PALSAR-2 mission and the planned Canadian Space Agency RADARSAT (C-frequency) constellation mission for technical reasons. 
Full polarimetry offers a solution to the depth of penetration problem as illustrated in Figure 7.

Figure 8 illustrates the direct solution to measure the frequency-dependent penetration considering full polarimetry SAR. Sigma-naught from high-density materials (metallic objects, rock outcrops and gravel bars of rivers) is by surface coherence scattering of the spatialcoherence convolution integral (Figure 8(a)). A RADAR send HH is backscattered as $\mathrm{HH}$, and send VV is backscattered as VV with no penetration to the volume below. In this case the 2-way travel time, $T_{1}$, whether HHHH or VVVV can be used as a temporal reference. Sigma-naught from low bulk density materials (soil and vegetation including the root zone) is by volume coherence scattering of the spatial coherence convolution integral (Figure $8(\mathrm{c})$ ). A RADAR send HH is backscattered VV after polarization rotation. The 2-way travel time in this case is $T_{2}$ such that

$$
T_{2}>T_{1}
$$

The first step is then to difference the raster-by-raster travel times in samescene RADAR image data,

$$
\Delta T=T_{2}-T_{1}
$$

Multiplying the 2-way time difference $\Delta T$ produces a raster-by-raster 1-way travel time difference,

$$
\Delta t=1 / 2 \Delta T
$$

Averaging $\Delta t$ in the RADAR image or region of interest produces a difference time statistic

$$
\Delta \tau=\frac{1}{N} \sum_{i=1}^{N} \Delta t_{i}
$$

Given that time is the most important variable and the velocity of the RADAR in the earth's atmosphere is known, attenuation of the speed of light, the simple geometric physical model (Figure 8(c)), can then recover the volumetric depth by one-, two- or three-layer cases as illustrated. With these depth estimates derived as such, a field experiment can validate the result of one-layer to threelayer depth for instance.

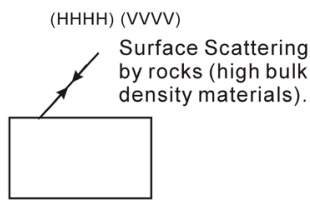

2-Way Travel Time, $\mathrm{T}$ $(\mathrm{HHHH}$

(a)

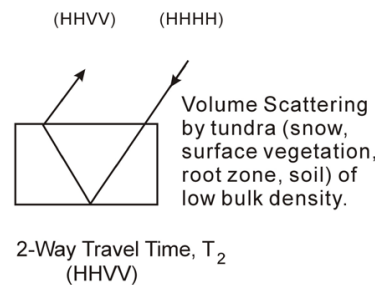

(b)

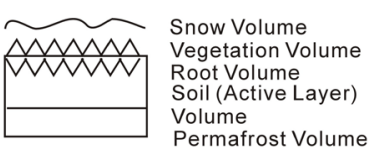

Permafrost Volume

(c)

Figure 8. Solution of the depth of penetration problem by considering the 2-way travel times of the full polarimetry SAR images and a simple physical model of a tundra-permafrost terrain. (a) Surface scattering; (b) Volume scattering; (c) Physical model. 


\section{Field Test Validation Experiment}

A field test validation proof-of-concept experiment is proposed to be located at two sites a few kilometers south of Dead horse, Alaska, near to the Dalton Highway and the other in the flood plain of the Sagavanirktok River (Figure 9).

In addition to the field test to validate our SAR L-frequency depth of penetration we can use both sites $\mathrm{C} 1$ and $\mathrm{S} 1$ to measure non-floodplain and floodplain geodetic elevation and surface property changes, respective. Additionally, human induced elevation changes of surface deformation and impacts to the ice wedge networks along the northern reach of the Dalton Highway can be accomplished by using UAVSAR, satellite borne PALSAR-2 with ground-based GNSS fine-scale measurements, Figure 9 and Figure 10. An emphasis is to characterize and measure post-flood response changes of the active layer, ice wedge and permafrost by way of both negative and positive feedbacks connected to human activities and infrastructure.

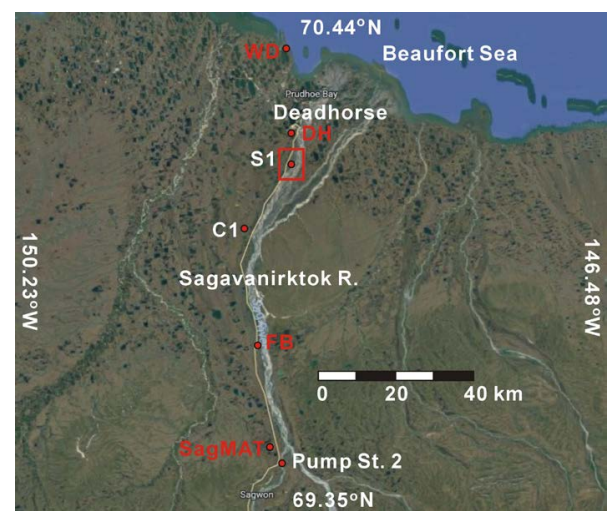

Figure 9. Field test sites $\mathrm{C} 1$ (control) and S1 (signal, ice wedge site) of the SAR L-frequency depth of penetration on tundra experiment. Red dots indicate permafrost borehole and surface meteorological observatories. Red square shows the location of $\mathrm{C} 1$ and S1. Permafrost borehole monitoring sites are designated DH (Deadhorse), FB (Franklin Bluffs), SagMAT and WD (West Dock).

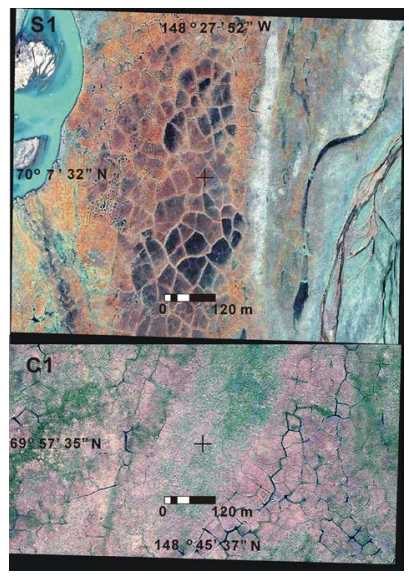

Figure 10. Worldview 3 images of ice wedge networks in the proposed sites S1 Sagavanirktok River floodplain and C1 control west, outside, of the floodplain (Figure 9). 
For fine-scale referencing we will incorporate Worldview-1, -2 and -3 for satellite photogrammetric geomorphometry. These image-pairs are provided through the National Geospatial-Intelligence Agency and Digital Globe web archive service with National Science Foundation support. These agencies together with the Ohio State University and the Polar Geospatial Center have produced the Alaska portion of the ArcticDEM (Digital Surface Model, contains vegetation height) at $2 \mathrm{~m}$ posting will be utilized for surface height change detection and evaluation and USGS $5 \mathrm{~m}$ posting InSAR DEM (bald-earth elevation model) [21] [22] [23]. The height accuracies of Worldview-1 and -2 are $0.33 \mathrm{~m}$, on average, and for Worldview-3 is $0.15 \mathrm{~m}$, on average [24] [25].

\subsection{Geodesy by Ground GNSS and Radar Reflector-Mesh Arrays}

To monitor and measure sub-meter scale surface deformation we will employ Synthetic Aperture Radar (SAR) reflector-mesh arrays at locations C1 and S1 (Figure 9 and Figure 10). The wire mesh elements of the arrays consist of heavy-gauge radar-reflective alloy geometrically arranged to produce higher-level backscatter and coherence (above $\mathrm{dB}$ noise level of the tundra) when irradiated by over-pass and slant-ranging SAR air and spaceborne systems. The wire-mesh reflectors are 1-meter squares, flexible and held to the surface by metal stakes, Figure 11. Being flexible allows the mesh interior to deform as the surface deforms. This allows each mesh to capture sub-meter morphology as the thawing ice wedge melts and enclosing permafrost degrades from below. The Control site $\mathrm{C} 1$ will be out-fitted with one-wing 3-element mesh-reflector array [26]. The offsets in the geometry of the array arms is intended to mitigate possible micro-topography induced auto-correlations of the backscatter waveforms that can lead to false-positive indications of surface deformation. Thus, over the threeyear period an evolution of the fine-scale centimeter geomorphology of the thawing ice wedge and permafrost from below can be captured and compared to the multi-pass SAR backscatter used to produce InSAR Line-of-Sight deformation maps. Coupled with GNSS measurements the maps will have mm-scale accuracy and precision of surface deformation and evolution.

Each site mesh-reflector array will be instrumented with miniature iSXBlue III+ GNSS dual channel (GPS and GLONASS) modular receivers and external antennas at ground level, Figure 11. These receivers are capable of accuracy and precession at the $1-\mathrm{cm}$ level. They operate autonomously and are accessible/programmable by iPhone and Android-phones. These receivers will provide for fine-time-scale surface deformation and surface environment state (and change of state). We will post-process their RINEX files with the NOAA CORS stations for 1-mm accuracy and precision network solution time-series over the project 3-year period. Array elements will be sequentially buried at site $\mathrm{C} 1$ to measured depths beneath the tundra (Figure 12). The depth beneath the tundra where reflector-mesh backscatter sigma- $0\left(\sigma_{0}\right)$ equals the tundra- $\sigma_{0}$ (HHVV $\sigma_{0}$, i.e. Background Noise Level) is the UAVSAR L-frequency depth of penetration. 


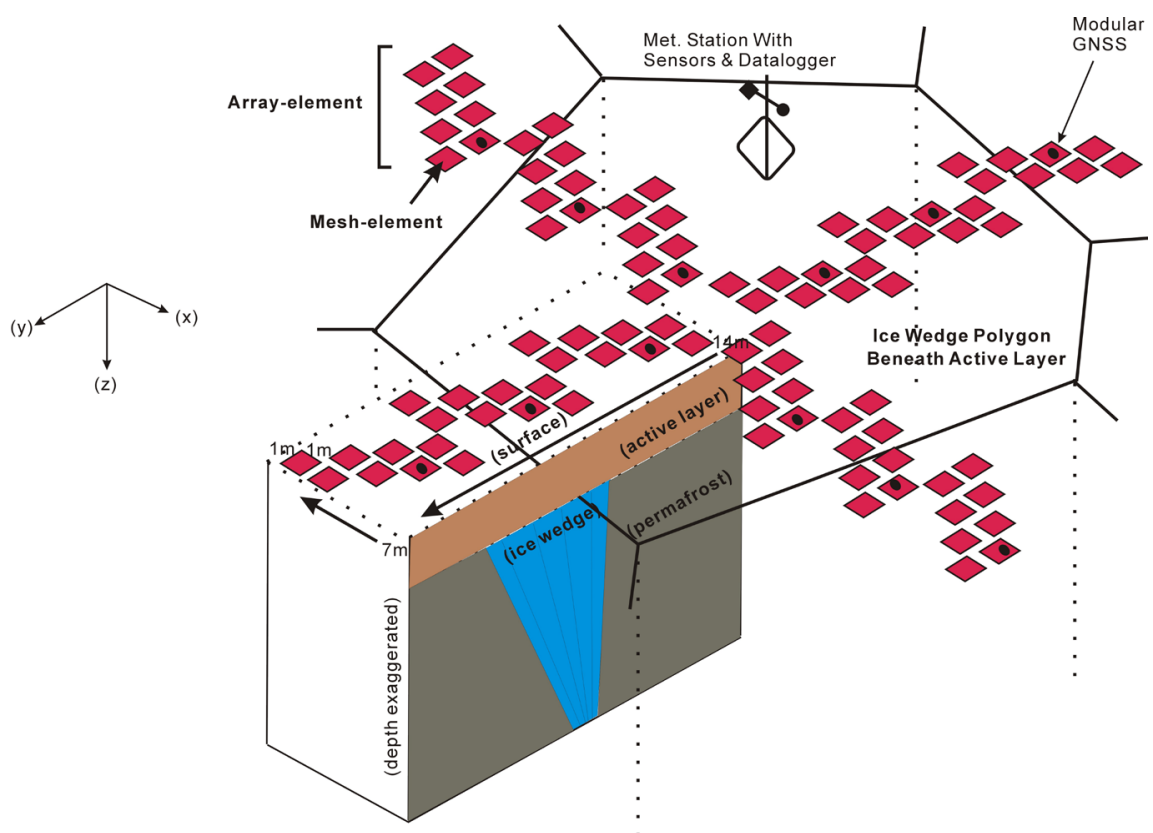

Figure 11. RADAR reflector-mesh array with schematic of ice wedge polygon within permafrost below the active layer at Site $\mathrm{S} 1$.

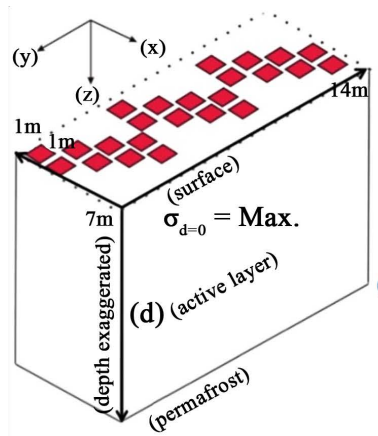

$\sigma$ is backscatter

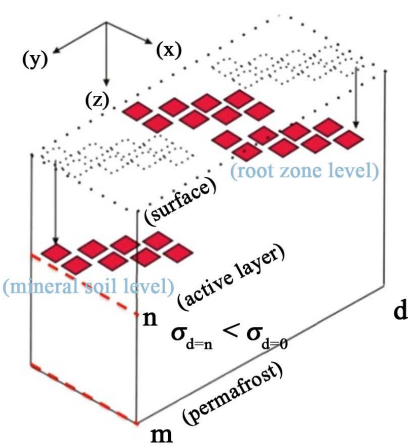

State 2

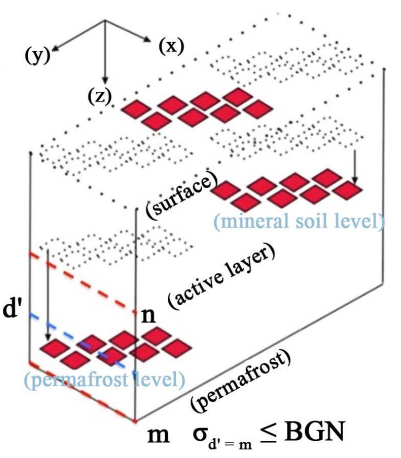

$\mathrm{d}^{\prime}=$ Penetration Depth

State 3

Figure 12. RADAR Reflector-Mesh Array Control Site. State 1, initial set-up, depth $(\mathrm{d})=$ 0. $\sigma_{0}$ is surface backscatter (maximum value, depending on HHHH, VVVV and HHVV polarizations). State 2, year 2, north and south array elements lower below tundra surface at depth $\mathrm{d}=\mathrm{n}$ for south array element where $\mathrm{n}<\mathrm{m}$ the depth of permafrost measured at the site. Backscatter from the south array element $\sigma_{\mathrm{d}=\mathrm{n}}<\sigma_{\mathrm{d}=0}$. State 3, year 3, south array element is lowered to depth $\mathrm{d}^{\prime} \leq \mathrm{m}$, and $\sigma_{\mathrm{d}^{\prime}=\mathrm{m}}$ is equal to the Background Noise (BGN) is invisible to the SAR and is the radar frequency penetration depth. The depth scale is exaggerated.

\subsection{Hypotheis Tests}

The ability to conduct repeatable measurements is the key for any science experiment. With our GNSS, InSAR and RADAR reflector-mesh array measurements we will conduct a test of hypothesis for science evaluation. This can be framed as a Null and Alternative Test of Hypothesis based on measurements of 
Surface Deformation Change (SDC).

\subsection{Hypotheis Test 1}

1) Null Hypothesis, $\mathrm{H}_{\mathrm{SDC}}=0$

This is the result where surface deformation change cannot be detected above the accuracy and precision of the methods employed.

2) Alternative Hypothesis, $\mathrm{H}_{\mathrm{SDC}} \neq 0$.

This is the result where surface deformation change can be detected above the accuracy and precision of the methods. The control-monitoring site for the evaluation of this test of hypothesis is $\mathrm{C} 1$, a reflector-mesh sight on the tundra outside of the Sagavanirktok River floodplain south of Deadhorse [26]. The outcome of the experiment will enable us to evaluate and test a second hypothesis of L-frequency Coherence and Backscatter Strength (CBS, depending on $\mathrm{HHHH}$, VVVV and HHVV polarization) on tundra.

\subsection{Hypotheis Test 2}

1) Hypothesis, $\mathrm{H}_{1}$ Array $\mathrm{CBS}>$ Tundra, i.e. surface coherence scattering,

2) Alternate Hypothesis, $\mathrm{H}_{0}$ Array $\mathrm{CBS}=$ Tundra.

In theory, the second hypothesis test should confirm the outcome of the first hypothesis test.

\section{Expected Experimental Results}

The experiment, expected to begin summer 2019, will allow for the direct validation of enhanced coherency and backscatter signal strength and determination of the depth of penetration of L-frequency UAVSAR on Arctic lowland tundra of the North Slope of Alaska. The elements of the reflector-mesh array are flexible. Over the project period the elements of reflector-mesh arrays can deform as the underlying permafrost and ice wedge network thaw and degrade and the active layer subsides. If late summer water percolates to the permafrost table and freezes the active layer can respond by a small amount of heave, which I will measure. Validation of the tundra L-frequency cross-polarization HHVV on tundra (RADAR soft target) and depth of penetration are needed parameters prior to attempting carbon-equivalent mass balance at regional scales.

\section{Errors and Uncertainties}

To control the derived Digital Surface Models (DSM, from Worldview 1 - 3) and LOS maps (from UAVSAR and Sentinel-1 A/B) I will employ the $2 \mathrm{~m}$ ArcticDEM and the $5 \mathrm{~m}$ USGS IfSAR Alaska DEM [21] [23]. The ArcticDEM is a stereo-photogrammetric Digital Surface Model that incorporates vegetation height and snow thickness variations during the period of Digital Globe EVWHS archive from 2010 to current-date. Regional registration control utilizes the Ice, Cloud and land Elevation Satellite (ICESat) Geoscience Laser Altimeter System (GLAS) GLA14 Land Surface Product of the ICES at seasonal campaigns from 
March 2003 to October 2009. The GLA14 product derives from the GLA06 Global Altimetry product. This particular product also includes variations of winter snow thickness as well as vegetation thickness [27]. The 5m USGS IfSAR Alaska DEM is derived through aircraft-based multi-frequency and multi-pass interferometry that allows for the removal of vegetation thickness thus yielding a "Bald-Earth" DEM.

The DEMs and LOS change maps I derive will also employ ICES at GLAS GLA06 Product datasets as reference for ground-control-points [16] [17] [28]-[33]. The GLAS datasets utilize the World Geodetic System reference ellipsoid WGS-84 and Geoid (EGM96/2008) and are consistent with the International Terrestrial Reference Frame (ITRF).

The reference for the measurements of this project is relative to reference ITRF EPOCH 2015 (EMG96/WGS 84) using multiple-deployed multi-channel GNSS receivers collocated to the NOAA CORS stations in Alaska. The GNSS receivers for this project utilize Channels L1, L2, L5 of GPS and GLONASS. GPS-only position solutions are degraded due to the NAVSTAR orbits at $55^{\circ}$ $\mathrm{N}-\mathrm{S}$ giving rise to coverage lapses and poor Atmosphere/Ionosphere corrections at locations above $55^{\circ}$, i.e. high latitudes [34]. GLONASS is polar-orbiting; therefore its solutions at locations of the high latitudes do not suffer this limitation.

\section{Conclusions}

RADAR has the capability to interact with low bulk density Earth materials including permafrost, vegetation, seasonal and perennial snow (firn) and glacier ice, and soils to retrieve information of the specific material properties. On Alaska's North Slope lowland tundra with carbon and ice rich permafrost undergoing thaw and degradation, understanding RADAR retrieval information will be key to deriving regional mass balance of carbon and water (gain, loss and transport) in the ground, ecosystem dynamics and the drivers of forcing and feedback linkages.

To understand the retrieval information using the aircraft SARs such as the JPL-NASA UAVSAR and satellite borne SARs such as PALSAR-2 et al. experiments must be performed to validate and verify the frequency-dependent depth of penetration. With the advent of full polarmetric SAR the frequency-dependent depth of penetration can be easily determined through consideration of the surface coherence relative to the volume coherence. With ground-based reflector-mesh antenna-array coupled with GNSS arrays at two sites south of Deadhorse, Alaska, we propose such an experiment test. The test sites include one within the Sagavanirktok River floodplain (lowland tundra with ice wedge polygon network) and one outside the floodplain (lowland tundra without ice wedge polygon network). This experiment will furthermore allow millimeter scale geodetic measurements of changes in the active layer (seasonally frozen ground), permafrost degradation and establish a framework for derivation of carbon- 
equivalent mass balance of the lowland tundra of the Alaska North Slope and elsewhere across the high latitude permafrost regions.

\section{Fund}

This work was funded by NASA ABoVE Grant NNX17AC57A.

\section{Conflicts of Interest}

The author declares no conflicts of interest regarding the publication of this paper.

\section{References}

[1] Scott, K.M. (1978) Effects of Permafrost on Stream Channel Behavior in Arctic Alaska. US Geological Survey Professional Paper 1068, 19 p.

[2] Kanevskiy, M., Shur, Y., Fortier, D., Jorgenson, M.T. and Stephani, E. (2011) Cryostratigraphy of Late Pleistocene Syngenetic Permafrost (Yedoma) in Northern Alaska, Itkillik River Exposure. Quaternary Research, 75, 584-596.

https://doi.org/10.1016/j.yqres.2010.12.003

[3] Levin, J. and Ashworth, P.J. (2014) The Negative Relief of Large River Floodplains. Earth-Science Reviews, 129, 1-23. https://doi.org/10.1016/j.earscirev.2013.10.014

[4] French, H.M. and Slaymaker, O. (1993) Ch. 1 Canada's Cold Landmass. In: French, H.M. and Slaymaker, O., Eds., Canada's Cold Environments, MaGill Queen's University Press, Quebec, 4-27.

[5] Barnes, P.W. and Reimnitz, E. (1976) Flooding of Sea Ice by Rivers of Northern Alaska. In: Williams Jr., R.S. and Carter, W.D., Eds., ERTS-1 a New Window on Our Planet: US Geological Survey Professional Paper 929, 356-359.

[6] Bigelow, B.B. (1998) Summary of Floods in the United States, January 1992 through September 1993: U.S. Geological Survey Water-Supply Paper 2499. In: Perry, C.A. and Combs, L.J., Eds., Alaska, May-August 1992, 115-118.

[7] Vimeo (2015) Dalton Highway Flooding Disaster: Viemo LLC. https://vimeo.com/album/3357427/page:1/sort:preset/format:thumbnail

[8] Federal Motor Carrier Safety Administration (FMCSA). https://www.fmcsa.dot.gov/emergency/alaska-declares-declaration-disaster-emerge ncy-due-unprecedented-flooding

[9] State of Alaska Press Release (2015) Disaster Declared for Dalton Highway Flooding.

https://gov.alaska.gov/newsroom/2015/04/disaster-declared-for-dalton-highway-flo oding/

[10] USGS (2015) National Water Information System.

http://nwis.waterdata.usgs.gov/usa/nwis/uv/?cb_00060=on\&cb_00065=on\&cb_0004 $5=$ on $\&$ cb_00020 $=$ on $\&$ cb_00010=on\&format $=$ gif_default $\&$ site_no $=15908000 \&$ perio $\mathrm{d}=$ \&begin_date $=2015-02-01$ \&end_date $=2015-06-12$

[11] NOAA (2015) National Weather Service National Centers for Environmental Prediction, Climate Prediction Center.

http://www.cpc.ncep.noaa.gov/products/archives/short_range/srarc.php

[12] Shur, Y., Kanevskiy, M., Walker, D.A., Jorgenson, T., Buchhorn, M., Raynolds, M.K. and Toniolo, H. (2016) Permafrost-Related Causes and Consequences of the Saga- 
vanirktok River Flooding in Spring 2015. Proceedings of the XI International Conference on Permafrost, Potsdam, 20-24 June 2016.

[13] Wood, R. (2015) Alaska Road Used to Haul Oil Supplies Reopens after Flooding: Fairbanks Daily News-Miner.

http://www.newsminer.com/news/alaska_news/alaska-road-used-to-haul-oil-suppli es-reopens-after-flooding/article_884ccf50-0bb9-11e5-a5c3-27cfceab8c34.html

[14] Alaska DOT \& FS (2016) Dalton Highway 2016 January through May: Changing Conditions. Alaska Business Monthly. http://www.akbizmag.com/Dalton-Highway-2016-January-through-May

[15] Avionics Department (2013) Electronic Warfare and Radar Systems Engineering Handbook (Unclassified), NAWCWD Technical Publication 8347. 4th Edition, Naval Air Warfare Center Weapons Division, Point Mugu, 455 p.

[16] Muskett, R.R. (2015) ICESat GLAS Elevation Changes and ALOS PALSAR InSAR Line-of-Sight Changes on the Continuous Permafrost Zone of the North Slope, Alaska. International Journal of Geosciences, 6, 1101-1115. https://doi.org/10.4236/ijg.2015.610086

[17] McCauley, J.F., Schaber, G.G., Breed, C.S., Grolier, M.J., Haynes, C.V., Issawi, B., Elachi, C. and Blom, R. (1982) Subsurface Valleys and Geoarchaeology of the Eastern Sahara Revealed by Shuttle Imaging Radar. Science, 218, 1004-1020. https://doi.org/10.1126/science.218.4576.1004

[18] McCauley, J.F., Breed, C.S., Schaber, G.G., McHugh, W.P., Issawi, B., Haynes, C.V., Grolier, M.J. and Kilani, A.E. (1986) Paleodrainages of the Eastern Sahara-The Radar Rivers Revisited (SIR-A/B Implications for a Mid-Tertiary Trans-African Drainage System). IEEE Transactions on Geoscience and Remote Sensing, 24, 624-648. https://doi.org/10.1109/TGRS.1986.289678

[19] Elachi, C., Brown, W.E., Cimino, J.B., Dixon, T., Evans, D.L., Ford, J.P., Saunders, R.S., Breed, C., Masursky, H., Mccauley, J.F., Schaber, G., Dellwig, L., England, A., Macdonald, H., Martin-Kaye, P. and Sabins, F. (1982) Shuttle Imaging Radar Experiment. Science, 218, 996-1003. https://doi.org/10.1126/science.218.4576.996

[20] Elachi, C., Cimino, J. and Settle, M. (1986) Overview of the Shuttle Imaging Radar-B Preliminary Scientific Results. Science, 232, 1511-1516. https://doi.org/10.1126/science.232.4757.1511

[21] Morin, P., Porter, C., Cloutier, M., Howat, I., Noh, M.-J., Willis, M., Bates, B., Willamson, C. and Peterman, K. (2016) ArcticDEM; A Publically Available, High Resolution Elevation Model of the Arctic. EGU General Assembly, Vienna, 17-22 April 2016, EPSC2016-8396.

[22] NSF (2015) National Geospatial-Intelligence Agency Support Development of New Arctic Maps. Press-Release 15-099, Arlington.

[23] Carswell, W.J. (2013) The 3D Elevation Program-Summary for Alaska. US Geological Survey Fact Sheet 2013-3083, Dept. of Interior, Washington DC.

[24] Mitchel, G. (2010) PhotoSat WorldView-2 Stereo Satellite DEM Comparison to a LiDAR DEM over the Garlock Fault in Southeast California. Digital Globe. http://www.photosat.ca/pdf/photosat_wv2_lidar_comparison_2010jun.pdf

[25] Mitchel, G. (2015) Highly Accurate Satellite Topographic Mapping Accuracy Study. PhotoSat Information Ltd.

http://www.photosat.ca/pdf/garlock-30cm-wv3-elevation-accuracy-report-mar2015. pdf

[26] Muskett, R.R. (2017) L-Band InSAR Penetration Depth Experiment, North Slope 
Alaska. Journal of Geoscience and Environment Protection, 5, 14-30. https://doi.org/10.4236/gep.2017.53002

[27] Atwood, D.K., Guritz, R.M., Muskett, R.R., Lingle, C.S., Sauber, J.M. and Freymueller, J.T. (2007) DEM Control in Arctic Alaska with ICESat Laser Altimetry. IEEE Transactions on Geoscience and Remote Sensing, 45, 3710-3720. https://doi.org/10.1109/TGRS.2007.904335

[28] Muskett, R.R., Lingle, C.S., Tangborn, W.V. and Rabus, B.T. (2003) Multi-Decadal Elevation Changes on Bagley Ice Valley and Malaspina Glacier, Alaska. Geophysical Research Letters, 30, 1857. https://doi.org/10.1029/2003GL017707

[29] Muskett, R.R., Lingle, C.S., Sauber, J.M., Post, A.S., Tangborn, W.V. and Rabus, B.T. (2008) Surging, Accelerating Surface Lowering and Volume Reduction of the Malaspina Glacier System, Alaska, USA, and Yukon, Canada, from 1972 to 2006. Journal of Glaciology, 54, 788-800. https://doi.org/10.3189/002214308787779915

[30] Muskett, R.R., Lingle, C.S., Sauber, J.M., Post, A.S., Tangborn, W.V., Rabus, B.T. and Echelmeyer, K.A. (2009) Airborne-Spaceborne DEM- and Laser AltimetryDerived Surface Elevation and Volume Changes of the Bering Glacier System, 1972 through 2006. Journal of Glaciology, 55, 316-326.

https://doi.org/10.3189/002214309788608750

[31] Muskett, R.R. and Romanovsky, V.E. (2009) Groundwater Storage Changes in Arctic Permafrost Watersheds from GRACE and in Situ Measurements. Environmental Research Letters, 4, Article ID: 045009.

[32] Muskett, R.R. and Romanovsky, V.E. (2011) Alaskan Permafrost Groundwater Storage Changes Derived from GRACE and Ground Measurements. Remote Sensing, 3, 378-397. https://doi.org/10.3390/rs3020378

[33] Muskett, R.R. (2014) ICESat-Derived Elevation Changes on the Lena Delta and Laptev Sea, Siberia. Open Journal of Modern Hydrology, 4, 1-9. https://doi.org/10.4236/ojmh.2014.41001

[34] Tegedor, J., Øvstedal, O. and Vigen, E. (2014) Precise Orbit Determination and Point Positioning Using GPS, Glonass, Galileo and BeiDou. Journal of Geodetic Science, 4, 65-73. https://doi.org/10.2478/jogs-2014-0008 